\title{
Article \\ Outdoor Atmospheric Microplastics within the Humber Region (United Kingdom): Quantification and Chemical Characterisation of Deposited Particles Present
}

\author{
Lauren C. Jenner ${ }^{1}$, Laura R. Sadofsky ${ }^{1}$, Evangelos Danopoulos ${ }^{1}$, Emma Chapman ${ }^{2}$, David White ${ }^{3}$ iD, \\ Rebecca L. Jenkins ${ }^{1}\left(\mathbb{D}\right.$ and Jeanette M. Rotchell ${ }^{2, *(D)}$ \\ 1 Hull York Medical School, University of Hull, Kingston upon Hull HU6 7RX, UK; hylj2@hyms.ac.uk (L.C.J.); \\ Laura.Sadofsky@hyms.ac.uk (L.R.S.); hyen7@hyms.ac.uk (E.D.); hyrj7@hyms.ac.uk (R.L.J.) \\ 2 Department of Biological and Marine Sciences, University of Hull, Kingston upon Hull HU6 7RX, UK; \\ e.chapman@hull.ac.uk \\ 3 Hull City Council, Air Quality Officer, Environmental Regulation, 33, Witham, \\ Kingston upon Hull HU9 1DB, UK; david.white@hullcc.gov.uk \\ * Correspondence: j.rotchell@hull.ac.uk; Tel.: +44-(0)1482-465333
}

\section{check for}

updates

Citation: Jenner, L.C.; Sadofsky, L.R.; Danopoulos, E.; Chapman, E.; White,

D.; Jenkins, R.L.; Rotchell, J.M. Outdoor Atmospheric Microplastics within the Humber Region (United Kingdom): Quantification and Chemical Characterisation of Deposited Particles Present. Atmosphere 2022, 13, 265. https:// doi.org/10.3390/atmos13020265

Academic Editor: James Cizdziel

Received: 17 December 2021

Accepted: 2 February 2022

Published: 4 February 2022

Publisher's Note: MDPI stays neutral with regard to jurisdictional claims in published maps and institutional affiliations.

Copyright: (c) 2022 by the authors. Licensee MDPI, Basel, Switzerland. This article is an open access article distributed under the terms and conditions of the Creative Commons Attribution (CC BY) license (https:// creativecommons.org/licenses/by/ $4.0 /)$.

\begin{abstract}
Atmospheric microplastics (MPs) have been consistently captured within air samples on a global scale. Locations with high human activity are reported to have high MP levels. An urban sampling site in the Humber region (U.K.) has been sampled over a 13-month period, providing a seasonal variation profile of MP levels, size, shape, and polymer types that humans are exposed to. Mean MP levels, measured using passive fallout into a container, were $3055 \pm 5072 \mathrm{MP} \mathrm{m}^{-2} \mathrm{day}^{-1}$ (1164 median). An increase in levels with a decrease in MP size was observed, consisting of mainly film-shaped MPs (67\%) that were polyethylene (31\%) and nylon (28\%) polymer types. No relationship between rainfall and MP fallout levels was observed. In parallel, MPs within five urbanised locations relevant to human exposure were characterised over a 2-week period. An overall MP mean (and standard deviation) of $1500 \pm 1279$ was observed (1012 median), from which petroleum resin accounted for $32 \%$ of MP polymer type, with a higher prevalence within industrial and roadside zones. These comprised mainly fragment $(52 \%)$ and film (42\%) shapes, and the MPs levels increased with decreasing particle size. The results provide novel information on characterising polymer levels and types, and can inform cellular toxicity studies, investigating the consequences of human MP exposure.
\end{abstract}

Keywords: microplastic; polymer; deposition; synthetic; outdoor; air; FTIR; urban

\section{Introduction}

The intentional and unintentional release of plastic waste leads to accumulation within environmental compartments and allows for their global transport [1]. Microplastics (MPs) are plastic particles, smaller than $5 \mathrm{~mm}$ in size [2], and can be produced through primary manufacturing or via secondary degradation of larger plastic products [1]. The resulting particles have been detected within aquatic [3], terrestrial [4], and atmospheric [5] compartments and have also been detected thousands of meters above ground level [6]. Additionally, MPs have been identified within homes, offices [7], drinking water [8], salt [9], and food meant for human consumption [10]. The ubiquitous nature of MPs has emphasised unavoidable human exposure, with MP inhalation being the most recent emerging cause for concern [11,12]. MPs have been observed within human lung tissue samples [13] and chemically identified in human lung cadaver samples [14], supporting inhalation as a route of exposure for MPs. It is now vital that all environments relevant to regular human exposure are investigated to gain a holistic view of the entire MP exposure likely encountered on a regular basis. 
The field of atmospheric MPs is emerging, and an array of sampling and laboratory techniques have been applied to such studies. A consensus is emerging that urbanised outdoor locations display high MP levels that range from 10-712 $\mathrm{MP} \mathrm{m}^{-2}$ day $^{-1}$ (Table 1). Suburban and rural outdoor levels range from 53-132 $\mathrm{MP} \mathrm{m}^{-2} \mathrm{day}^{-1}$ (Table 1). However, there are conflicting reports regarding the types and characteristics of MPs that are most common, with fibrous MPs being the dominant shape according to some studies [15,16], and fragmented MPs for others [17,18]. Plastic polymer types that dominate sampling locations also differ, for instance, some report polyethylene (PE) $[16,17,19]$ as the predominant plastic, whilst others report polyacrylonitrile (PAN) [20], polyethylene terephthalate (PET) [15,21,22], polystyrene (PS) [18], and polyester (PES) [23]. Such investigations highlight the need to establish the levels, plastic types, sizes, and shapes that are present within the air.

Table 1. Summary of studies reporting outdoor atmospheric microplastic deposited samples. Abbreviations: EVA, ethylene vinyl acetate; PA, polyamide (nylon); PAN, polyacrylonitrile; PE, polyethylene; PES, polyester; PET, polyethylene terephthalate; PP, polypropylene; PP/PE, polypropylenepolyethylene co-polymer; PS, polystyrene; PVC, polyvinylchloride; resin, including alkyd, hydrocarbon and phenoxy resin.

\begin{tabular}{|c|c|c|c|c|}
\hline Reference & $\begin{array}{c}\text { Sample Location } \\
\text { (No. Sampling Sites) }\end{array}$ & $\begin{array}{c}\text { Total Sampling } \\
\text { Duration }\end{array}$ & $\begin{array}{l}\text { Dominant MP Types } \\
\text { (Total Present) }\end{array}$ & $\begin{array}{c}\text { Average } \mathrm{MP} \mathrm{m}^{-2} \mathrm{day}^{-1} \\
\text { (Range) }\end{array}$ \\
\hline [20] & Urban (1) & 1 month & $\begin{array}{c}\text { PAN, PET, PA } \\
\text { (15) }\end{array}$ & $\begin{array}{c}712 \pm 162 \text { mean } \pm S D \\
(575-1008)\end{array}$ \\
\hline [17] & $\begin{array}{l}\text { Urban (3) } \\
\text { Rural (3) }\end{array}$ & 3 months & $\begin{array}{l}\text { PE, EVA } \\
(4)\end{array}$ & $\begin{array}{c}261 \text { median } \\
247 \text { median } \\
137 \text { median } \\
331 \text { median } \\
512 \text { median } \\
343 \text { median } \\
275 \text { overall median } \\
(137-512)\end{array}$ \\
\hline [16] & Urban (3) & 3 months & $\begin{array}{l}\text { PE, PP, PS } \\
\text { (3) }\end{array}$ & $\begin{array}{c}36 \pm 7 \text { mean } \pm S D \\
(175-313)\end{array}$ \\
\hline [15] & $\begin{array}{c}\text { Urban (1) } \\
\text { Suburban (1) }\end{array}$ & $\begin{array}{l}13 \text { months } \\
5 \text { months }\end{array}$ & $\begin{array}{l}\text { PET, co-polymers, PA } \\
\text { (3) }\end{array}$ & $\begin{array}{c}110 \pm 96 \text { mean } \pm S D \\
(2-355) \\
53 \pm 38 \text { mean } \pm S D\end{array}$ \\
\hline [18] & Rural, remote (1) & 5 months & $\begin{array}{c}\text { PS, PE, PP } \\
\quad(>5)\end{array}$ & $365 \pm 69$ mean $\pm S D$ \\
\hline [23] & Urban (1) & 9 months & $\begin{array}{c}\text { PES, PP, PE, PVC } \\
(6)\end{array}$ & $\begin{array}{c}10 \pm 8 \text { mean } \pm S D \\
(0-30)\end{array}$ \\
\hline [22] & Urban (1) & 12 months & $\begin{array}{c}\text { PET, PAN, PP, PA, resin } \\
(>8)\end{array}$ & $114 \pm 40$ mean \pm SD \\
\hline Present study & Urban (1) & 13 months & PE, nylon, PET (25) & $\begin{array}{c}3055 \pm 5072 \text { mean } \pm S D \\
(1164 \text { median })\end{array}$ \\
\hline Present study & Urban (5) & 2 weeks & resin, $\mathrm{PET}, \mathrm{PP}, \mathrm{PP} / \mathrm{PE}$ & $\begin{array}{c}1500 \pm 1279 \text { mean } \pm \text { SD } \\
(1014 \text { median })\end{array}$ \\
\hline
\end{tabular}

This study determines the temporal variation in levels and types of MPs evident at one urban sampling site over a 13-month sampling period (including the SARS-CoV lockdown), within the city of Kingston upon Hull, U.K. In parallel, the MP profile over a 2-week time span for five sites; residential, city centre, industrial, commercial roadside, and a location in which all are relevant, has also been conducted. Having representative outdoor airborne MP levels and characteristic data from within a city environment can 
inform realistic human cellular toxicity studies, to investigate the consequences of MP inhalation with respect to MP levels, polymer type, shape, and size ranges.

\section{Material and Methods}

\subsection{Passive Sampling}

Using guidance from the Hull City Council (HCC) air quality monitoring department, five sampling locations were selected, representing different zones that humans are commonly exposed to (Figure 1). Site 1 ("A63") is located along a stretch of road (the A63), with heavy traffic flow in which blocks of residential flats, shops, offices, the city centre, and industrial units are all in close vicinity. Site 2 ("roadside commercial") is situated on a city centre road that has a heavy flow of traffic, as well as numerous commercial outlets and a police station. Site 3 ("industrial") is in an industrial zone in which nearby units produce furniture, paper, and paint products. Site 4 ("city centre") is in the centre of Kingston Upon Hull, important for transport, commercial use, and entertainment. Site 5 ("residential") represents a residential zone, including housing and student accommodation, as well as nearby playing fields.

Continuous passive sampling was conducted from October 2019 until October 2020, which included a period of national lockdown, affecting the sampling months of April and May (2020). Five rain samplers (Palmex Ltd., Zagreb, Croatia) were secured at head height, considering the placement of the inlet at the top of the sampling device. In practice, this was approximately $1.8 \mathrm{~m}(1.5-2.0 \mathrm{~m})$ from the ground with the aid of council street fixtures such as the tops of fences. Each location was individually assessed to avoid wind, shadow from buildings or vegetation, and minimise air movement disturbance. Ultimately, the samplers were placed in locations that best represented the zone type, but also in locations that avoided theft and damage to the samplers. The surface area $\left(0.014 \mathrm{~m}^{2}\right)$ of the sampler was calculated using the diameter of the opening funnel $(0.135 \mathrm{~m})$. The stainless-steel housing exterior of the sampler supported an opening funnel in which deposited environmental particles and precipitation could enter, travel through an intake tube, and deposit within a $3 \mathrm{~L}$ polyvinylchloride (PVC) bottle, ensuring no evaporation. A metal mesh grid (pore size $3 \mathrm{~mm}$ ) placed inside the funnel opening prevented large particles and objects from blocking the sampler. After each 14-day sampling period (each month), the PVC bottle was unscrewed from the sampler and sealed tightly with a PVC lid. The inside and sides of the rain sampler were then thoroughly rinsed with MilliQ ultrapure water (Sigma-Aldrich, Gillingham, U.K.) before another identical PVC bottle was screwed into the sampler for the subsequent sampling period.

Rainfall data was obtained by measuring the amount of rainfall (to the nearest $10 \mathrm{~mL}$ ) within the PVC containers at the end of the 2-week sampling period. The sampler design ensured that no evaporation occurred, allowing rainfall data to be collected on a site-specific level throughout the city, rather than acquiring regional online data. The sampling period included a national lockdown that occurred between the months of April and May 2020, during which only key workers were permitted to travel and a significant proportion of the local population worked from home. Phasing out of the national lockdown occurred from May, in which people were allowed to return to work, schools started to reopen (June 2020), and nonessential shops and venues reopened (June-July). Hull entered a further tier 2 local lockdown during the month of October (2020); however, sampling had finished. 




(B)

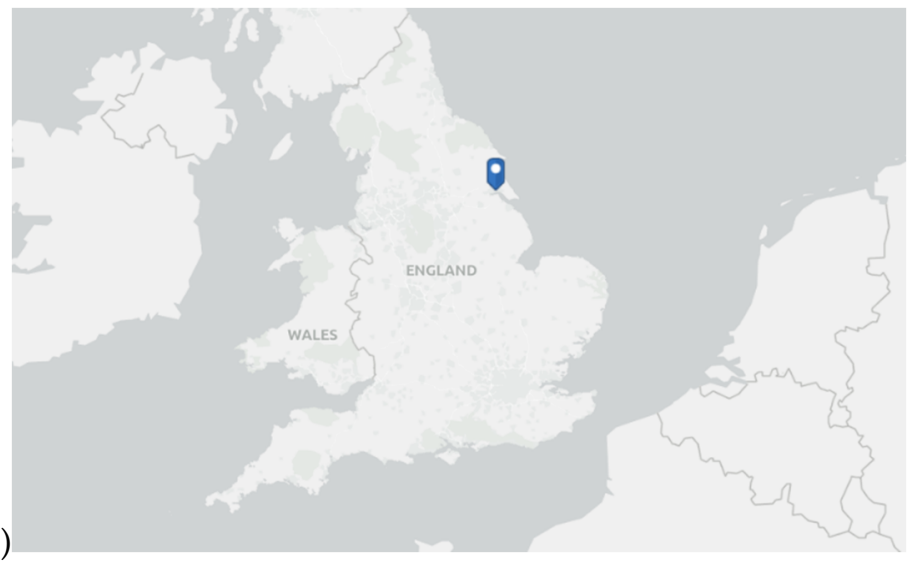

Figure 1. Map of the sampling locations chosen for atmospheric deposition sampling. (A). The sampling sites within Kingston upon Hull: A63 (Site 1), roadside commercial (Site 2), industrial (Site 3), city centre (Site 4), and university district (Site 5). (B). The location within the United Kingdom.

\subsection{Sample Preparation}

Site 1 samples were analysed for the duration of the study ( 13 months, $\mathrm{n}=13$, 14 October 2019-26 October 2020). Additionally, one sample from each of the five sampling locations was analysed, representing the same 14-day sampling period (17 February 2020-2 March 2020, prior to the national lockdown period). Many of the remaining samples were used during pilot studies in which method optimisation was achieved. The volume of rainfall (to the nearest $10 \mathrm{~mL}$ ) within each PVC bottle was recorded. Each sample was decanted and vacuum filtered onto mixed cellulose ester membrane filters (MCE), $47 \mathrm{~mm}$ diameter and $5 \mu \mathrm{m}$ pore size (MERCK, Gillingham, UK). Filters were dried and stored in sealed Petri dishes in the dark at room temperature. 
Samples were digested in three bulks (bulk 1 and 2 comprised Site 1 longitudinal samples, bulk 3 comprised the Site 2-5 samples). For each sample, one quarter of the sample filter was randomly selected for analysis. The quarter was cut and placed into a precleaned $1 \mathrm{~L}$ conical flask, and prefiltered $200 \mathrm{~mL}$ of $30 \%$ hydrogen peroxide $\left(\mathrm{H}_{2} \mathrm{O}_{2}\right)$ added. For procedural blanks (total $=4, \mathrm{n}=2$ for bulk 1 and $2, \mathrm{n}=2$ for bulk 3 ), that underwent every stage of laboratory sample preparation, a clean MCE filter was cut, and the quarter added to a $1 \mathrm{~L}$ conical flask, along with $200 \mathrm{~mL}$ of $\mathrm{H}_{2} \mathrm{O}_{2}$. Conical flasks were sealed with aluminium tin foil, labelled, and placed in a shaking incubator for 10 days $\left(55^{\circ} \mathrm{C}, 65 \mathrm{rpm}\right.$ [24]). Samples were vacuum filtered onto aluminium oxide (Anodisc) filters, $47 \mathrm{~mm}$ diameter and $0.2 \mu \mathrm{m}$ pore size (MERCK, Gillingham, UK). Sample Anodisc filters were placed in sealed Petri dishes, allowed to dry, and stored in the dark at room temperature.

\section{3. $\mu$ FTIR Analysis}

Each sample filter was placed directly onto the $\mu$ FTIR platform for particle characterisation. One half of each sample was randomly sectioned and analysed, except for two samples in which heavy particle load dictated that one quarter of the filter undergo analysis. Extrapolation of the data was later conducted. The length (largest side) and width (second largest side) was recorded for every particle above $5 \mu \mathrm{m}$. Particles with a length larger than $300 \mu \mathrm{m}$ were recorded as "> $>300 \mu \mathrm{m}$ " due to the selection tool size limit and field of view. Particles were sorted into shape categories: fibre, film, fragment, foam, and sphere [24,25]. Particles with a length to width ratio $>3$ were categorised as fibres [26]. For every particle characterised, chemical composition analysis was also conducted to identify the polymer type. This led to a total of 9983 particles undergoing analysis including the temporal and spatial variation studies, of which 3275 (representing 33\% of the total) particles were identifiable ( $>70 \%$ match). $\mu$ FTIR analysis was conducted in transmission mode (Nicolet iN10, ThermoFisher, Waltham, MA, USA), equipped with a liquid nitrogen cooling system. The cooled MCT detector allows for analysis of particles accurately to $3 \mu \mathrm{m}$ in size, although the filter pore size cut-off used was $5 \mu \mathrm{m}$. A background reference spectrum was taken before immediate analysis of each sample particle. A scan number of 64 and a spectral range of 4000-1250 $\mathrm{cm}^{-1}$ was applied. No observational criteria [3] was applied to select suspected MPs for analysis. Instead, all particles $>5 \mu \mathrm{m}$ were included in analysis. A library match index (Omnic Picta, Omnic Polymer Libraries) of $\geq 70 \%$ was chosen as a quality threshold, and particles below were not included in the results presented.

\subsection{Quality Control and Assurance}

Strict quality control measures were employed to monitor background MP contamination levels. Field blanks $(n=5)$ monitored contamination due to the opening of the PVC bottle during bottle replacement at each of the sampling sites. Procedural blanks $(\mathrm{n}=4)$ quantified any contamination during the sample preparation stages of laboratory processing, in which procedural blanks mimicked the digestion and filtration steps. Laboratory blanks $(n=17)$ quantified any contamination during $\mu$ FTIR analysis, in which an Anodisc filter was opened for the same period as each sample undergoing analysis. Therefore, contamination was monitored from every possible environment that each sample was exposed to (blank results are detailed in Supplementary Table S1). Field, procedural, and lab blank results for each sample were combined (as the "blank correction") and used in later adjustments to account for background contamination (Supplemental Information Methods 1).

Strict quality assurance measures were also used to restrict background MP contamination. All equipment and glassware used were first washed by hand before a dishwasher cycle using distilled water and finally a triple rinse using MilliQ water. The MilliQ water and $\mathrm{H}_{2} \mathrm{O}_{2}$ used during digestion were triple-filtered using glass fibre (GF6) filters (GE Healthcare Life Sciences, Marlborough, MA, USA). All reagents and equipment were always covered with aluminium tin foil lids and a small opening made when pouring. During pouring and filtering of samples, triple rinsing of containers with MilliQ water was 
conducted to avoid sample particle loss. A fume cupboard was used during most stages of the laboratory processing, with the power off to minimised air flow. Other than the PVC sampler (considered during field blanks), safety goggles, and nitrile gloves, plastic equipment was avoided by using an all-glass vacuum filtration kit, glass Petri dishes, a cotton laboratory coat, and glass or metal laboratory equipment. Laboratory work was conducted at times of low activity and $\mu$ FTIR analysis conducted in a single-person room. Windows and doors were closed with no other ventilation. Three random new Anodisc filters were chosen for $\mu$ FTIR analysis, in which no particles were identified to rule these out as a source of contamination. All fieldwork sampling and sample preparations were conducted by the primary researcher. The $\mu$ FTIR analyses was conducted "blind", by labelling samples anonymously and random allocation to one of four researchers.

\subsection{Statistical Analysis}

It was assumed that an even particle distribution occurred during the filtration process, and that the analysed portion of the filter represented the whole filter, after extrapolation (multiplied by 8 for most samples, or by 16 for the two samples with a heavy particle load). To convert the number of MPs per filter into meter squared, rather than surface area of the sampling device opening area, a correction factor $\left(1 / 0.014 \mathrm{~m}^{2}\right)$ was used. A final division of 14 was applied to represent one day:

$$
\mathrm{MP} \mathrm{m}^{-2} \text { day }^{-1}=(\mathrm{MP} \text { on whole filter } \times 71.43) / 14
$$

Results were adjusted using a limit of detection (LOD) and limit of quantification (LOQ) approach $[24,27]$ (Supplementary Information Method 1). The background contamination detected during the field, procedural, and laboratory blanks were combined to give an overall value of likely contamination for each polymer type. Only MPs detected above the LOD/LOQ were included within the final levels to provide the highest quality threshold available within atmospheric MP literature.

All data were determined not normally distributed, using SPSS with a Shapiro-Wilk test and either a Spearman's correlation or Kruskal-Wallis test applied. To test for a relationship between rainfall and particle fallout, as well as the rainfall and MP levels, a Spearman's correlation test was applied. To test for significant differences between sampling sites, Kruskal-Wallis tests were applied. A significance of $p=0.05$ was applied, and extreme significance of $p=0.005$.

\section{Results}

\subsection{Temporal Variation in the Atmospheric Deposition of MP Levels and Types at Sampling} Site 1 ("A63")

MPs were identified within all deposited samples from Site 1 (A63) $(\mathrm{n}=13)$ (Figure 2). The average deposition rate of all particles was $11,278 \pm 15,025$ particles $\mathrm{m}^{-2}$ day $^{-1}$ (ranging from 1429-57,471) (5551 median). After LOD/LOQ adjustments, the average deposition rate of MPs was $3055 \pm 5072 \mathrm{MP} \mathrm{m}^{-2}$ day $^{-1}(79-18,996)$ (1164 median) (Table 2) (Supplementary Figure S1). A correlation relationship between the rainfall (Figure 2) collected within the sampler and the atmospheric fallout captured was investigated using a Spearman's correlation test, with no significance. Additionally, a Spearman's correlation relationship between rainfall and MP deposition was investigated, again with no significance difference detected.

With respect to MP shape, film-shaped were the most abundant $(67 \%)$, followed by fragment (24\%) and fibrous (9\%) (Figure 3A). Film-shaped MPs had a mean level of $2151 \pm 3880 \mathrm{MP} \mathrm{m}^{-2}$ day $^{-1}(82-14,368)$ and were identified within every sample from Site 1. Fragmented MPs had a mean MP of $763 \pm 997 \mathrm{MP} \mathrm{m}^{-2}$ day $^{-1}$ and were identified in all but one sample. Fibrous MPs had a mean MP level of $273 \pm 487 \mathrm{MP} \mathrm{m}^{-2}$ day $^{-1}$ and were identified in all but one sample. 


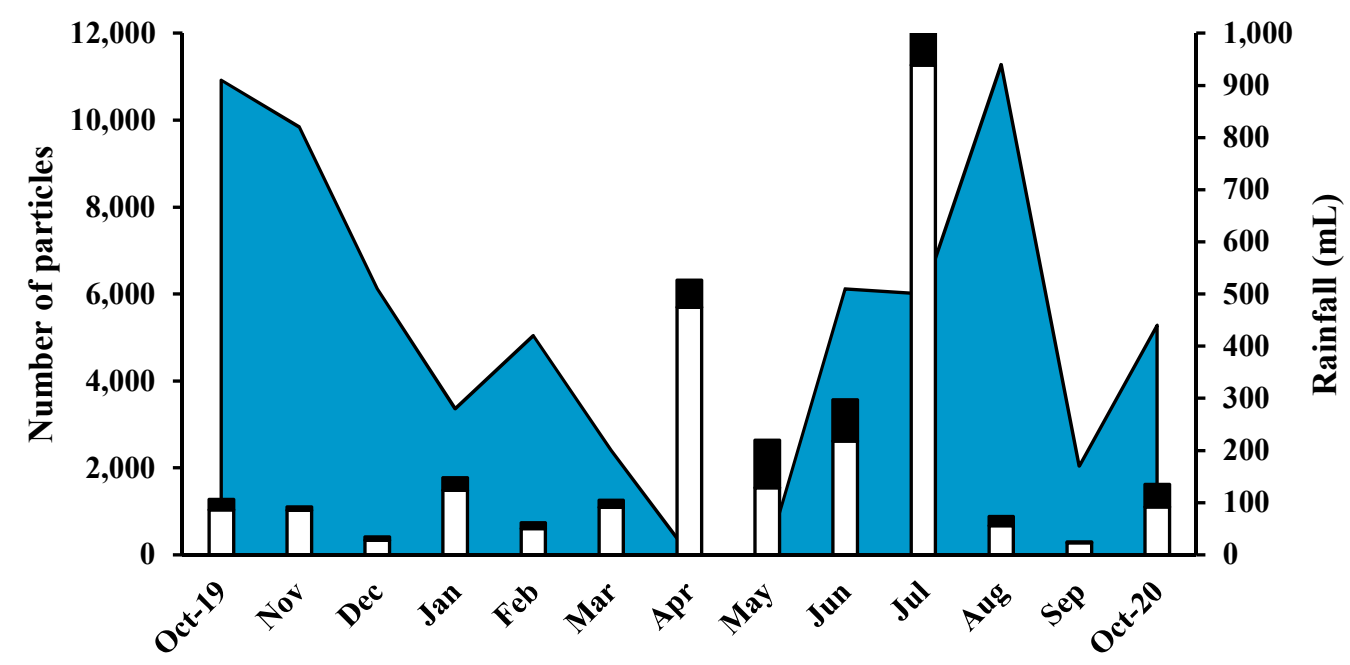

Sampling month

$\square$ Rainfall $\square$ Particles on filter aMPs on filter

Figure 2. Total number of particles and MPs identified, within the 2-week sampling period, for sampling Site 1 (A63). The total rainfall during each 2-week sampling period is presented alongside. April and May coincided with an official SARS-CoV lockdown.

Table 2. MP levels detected at Site 1, and from all five sampling sites, before and after LOD and LOQ adjustments.

\begin{tabular}{|c|c|c|}
\hline Site 1 Sampling Month & $\begin{array}{c}\text { MP m }^{-2} \text { day }^{-1} \\
\text { (No Adjustments) }\end{array}$ & $\begin{array}{c}\text { MP m }^{-2} \text { day }^{-1} \\
\text { (LOD LOQ Adjusted) }\end{array}$ \\
\hline October 2019 & 1225 & 1164 \\
\hline November & 408 & 316 \\
\hline December & 367 & 308 \\
\hline January & 1469 & 1446 \\
\hline February & 694 & 603 \\
\hline March & 857 & 799 \\
\hline April & 3184 & 3086 \\
\hline May & 5551 & 5494 \\
\hline June & 4857 & 4715 \\
\hline July & 19,266 & 18,996 \\
\hline August & 1061 & 917 \\
\hline September & 82 & 79 \\
\hline October 2020 & 2612 & 2597 \\
\hline Mean \pm SD(median) & $\begin{array}{c}3203 \pm 4926 \\
(1225 \text { median })\end{array}$ & $\begin{array}{c}3055 \pm 5072 \\
(1164 \text { median })\end{array}$ \\
\hline February sampling site & $\begin{array}{c}\mathrm{MP} \mathrm{m}^{-2} \mathrm{day}^{-1} \\
\text { (no adjustments) }\end{array}$ & $\begin{array}{c}\mathrm{MP} \mathrm{m}^{-2} \mathrm{day}^{-1} \\
\text { (LOD LOQ adjusted) }^{-1}\end{array}$ \\
\hline Site 1 (A63) & 694 & 603 \\
\hline Site 2 (Roadside) & 3633 & 3617 \\
\hline Site 3 (Industrial) & 1755 & 1746 \\
\hline Site 4 (City Centre) & 1020 & 1012 \\
\hline Site 5 (Residential) & 531 & 522 \\
\hline $\begin{array}{l}\text { Mean } \pm \text { SD } \\
(\text { median })\end{array}$ & $\begin{array}{c}1527 \pm 1268 \\
(1012 \text { median })\end{array}$ & $\begin{array}{c}1500 \pm 1279 \\
(1012 \text { median })\end{array}$ \\
\hline
\end{tabular}


With respect to MP size ranges, an increase in MP levels was associated with decreasing MP length (Figure 3B). The most prevalent length category was $21-30 \mu \mathrm{m}(20 \%)$, and most MPs (52\%) were $<50 \mu \mathrm{m}$ in length (Figure 3B). While MPs with a length $>300 \mu \mathrm{m}$ were present in all shape categories, 67\% of these largest particles were fibrous (long but thin). An increase in MP levels with decreasing width was observed at Site 1 (A63) (Figure 3C). The most prevalent width categories were 11-20 $\mu \mathrm{m}(24 \%)$ and $21-30 \mu \mathrm{m}(26 \%)$. A total of $67 \%$ of MPs had a width of $<40 \mu \mathrm{m}$. The smallest MP length recorded in this study was an $8 \mu \mathrm{m}$ long PE fragment. The smallest MP width recorded was a PE fibre with a $5 \mu \mathrm{m}$ width.

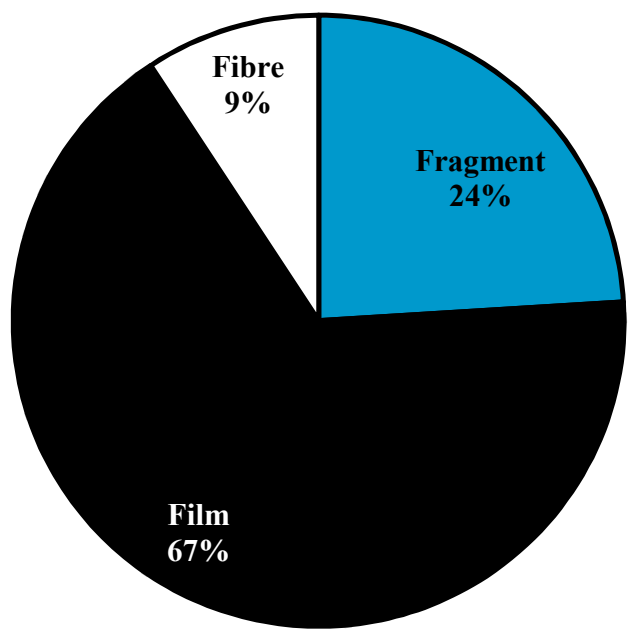

(A)

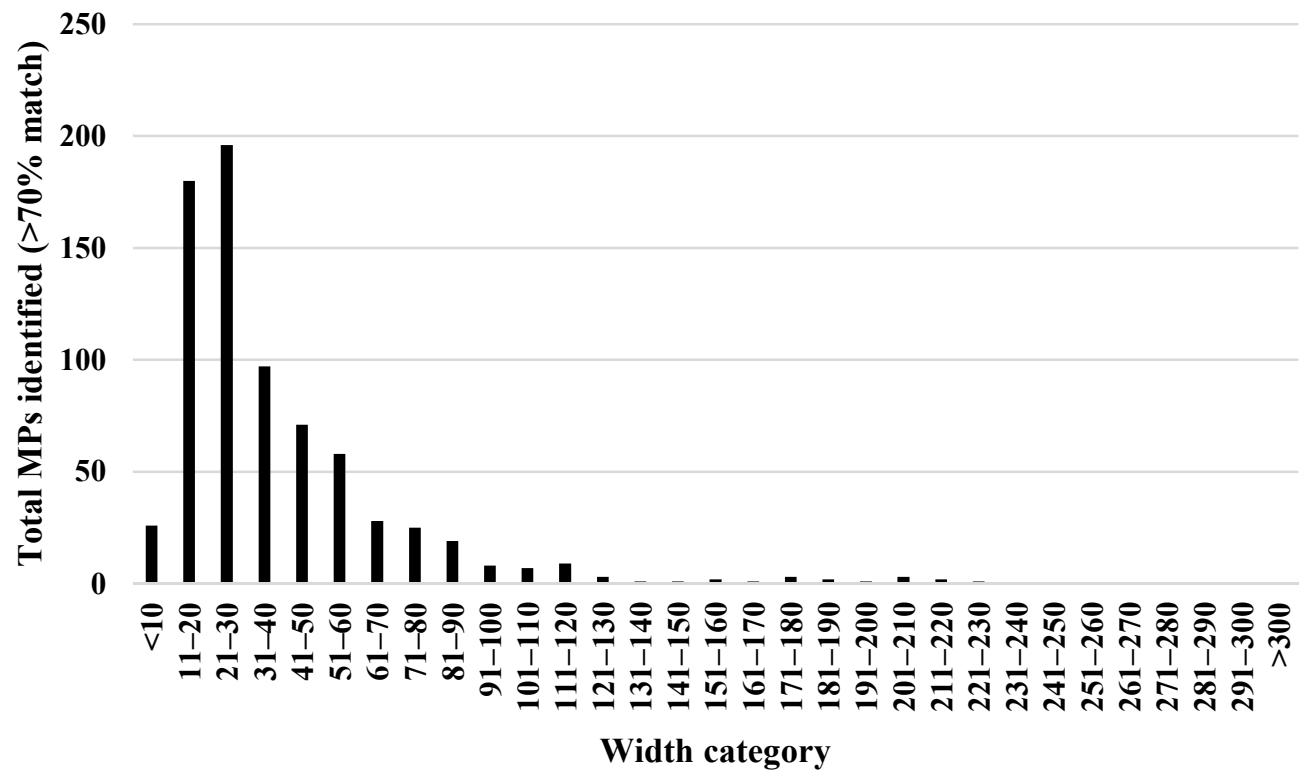

(B)

Figure 3. Cont. 


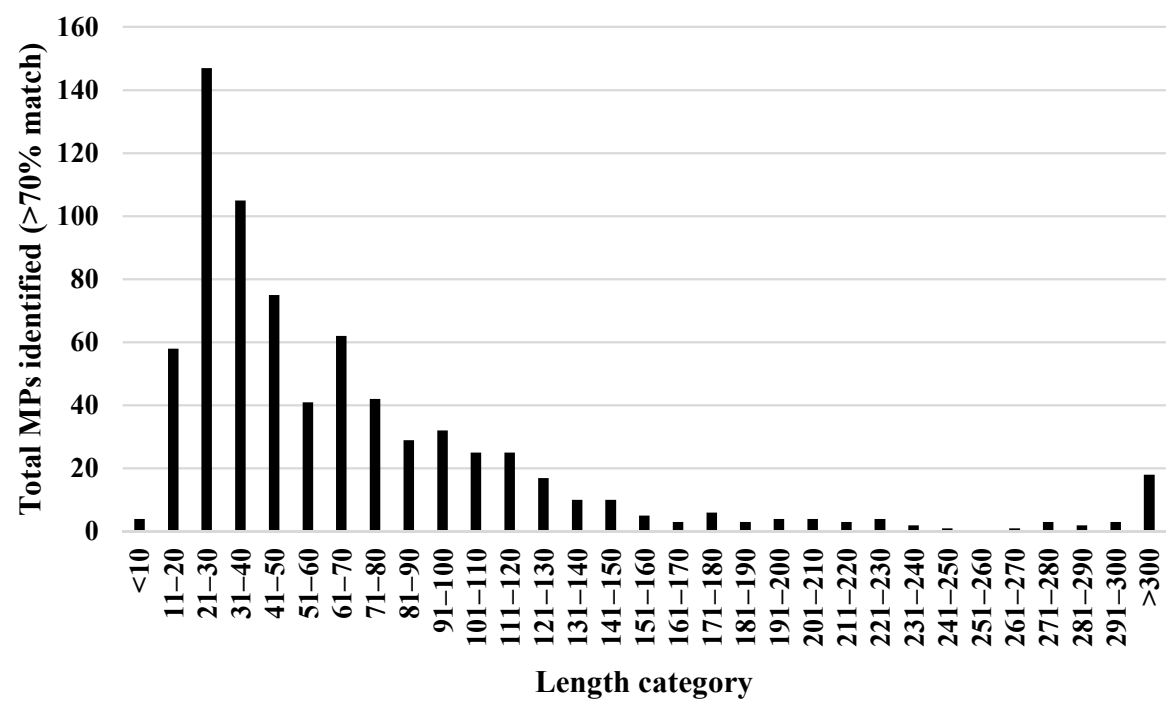

(C)

Figure 3. MP characteristics observed in the atmospheric samples obtained from sampling Site 1 (A63): (A) shape, (B) length, and (C) width.

The overall MP polymer composition of samples detected across the 13-month study at Site 1 (A63) samples was predominantly PE (31\%) and nylon (28\%), with 25 different polymer types identified (Figure 4). Overall, MPs accounted for $26 \%$ of the particles that were identifiable. Film-shaped MPs were predominantly PE (42\%) and nylon (35\%). Fragmented MPs displayed a more varied MP polymer type, with PET (15\%), PP/PE (11\%), PE $(10 \%)$, nylon $(9 \%)$, PTFE $(9 \%)$, and resin $(9 \%)$ the most abundant. Fibrous MPs were predominantly nylon (32\%), PE (16\%), PET (9\%), and acrylic (9\%).

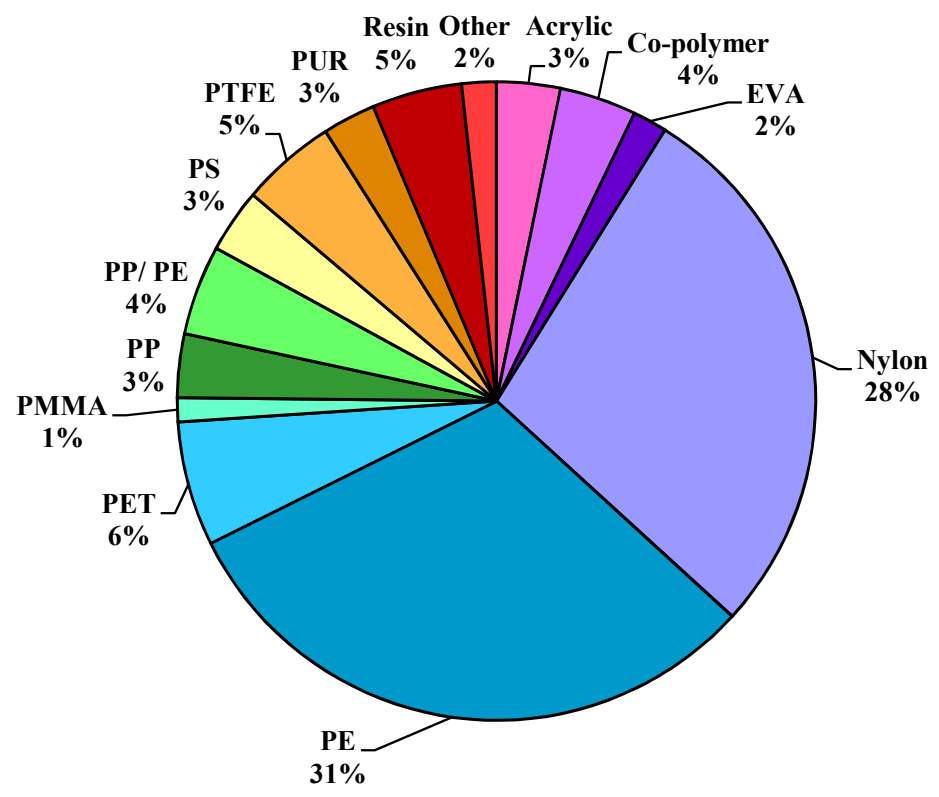

Figure 4. MP polymer types detected at sampling Site 1 (A63) throughout the 13-month sampling period. Abbreviations: EVA, ethylene vinyl acetate; PE, polyethylene; PET, polyethylene terephthalate; PMMA, polymethylmethacrylate; PP, polypropylene; PP/PE, polypropylene-polyethylene co-polymer; PS, polystyrene; PTFE, polytetrafluoroethylene; PUR, polyurethane; resin, including alkyd, hydrocarbon, and phenoxy resin. 
3.2. Spatial Variation in Atmospheric Deposition of MP Levels and Types across all Sampling Sites (1-5)

MPs were identified in samples from all five sampling sites. After LOD/LOQ adjustments, the total MP levels for each site were as follows: Site 1 (A63): $603 \mathrm{MP} \mathrm{m}^{-2} \mathrm{day}^{-1}$; Site 2 (roadside commercial): $3617 \mathrm{MP} \mathrm{m}^{-2}$ day $^{-1}$; Site 3 (industrial): $1746 \mathrm{MP} \mathrm{m}^{-2}$ day $^{-1}$; Site 4 (city centre): $1012 \mathrm{MP} \mathrm{m}^{-2}$ day $^{-1}$; Site 5 (residential): $522 \mathrm{MP} \mathrm{m}^{-2}$ day $^{-1}$. The average MP levels detected during the February 2-week period, across the five sampling sites, was $1500 \pm 1279$ (1012 median) (Table 2) (Figure 5), and no significant difference between these sites was observed.

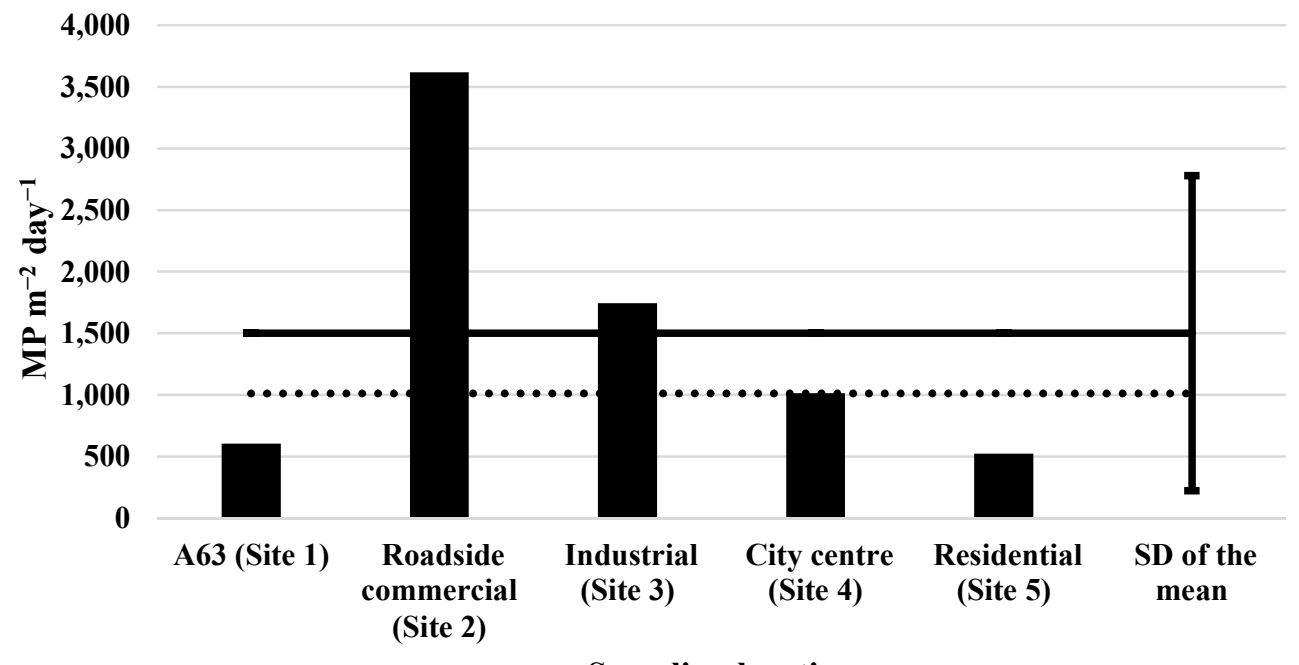

Sampling location

$\longrightarrow$ Mean MP concentration

-..... Median MP concentration

Figure 5. MP levels from the sampling month of February 2020, across all five sampling sites (after LOD LOQ adjustments). The solid line represents the mean MP level ( $\mathrm{MP} \mathrm{m}^{-2} \mathrm{day}^{-1}$ ) from the five sampling sites, and standard deviation of the mean included. The dotted line represents the median MP level (MP m ${ }^{-2}$ day $^{-1}$ ) from the five sampling sites.

From the five sampling sites, the most predominant MP shape was fragment (52\%), followed by film (42\%) and fibre (6\%) (Supplementary Figure S2A). With respect to MP size ranges, an increase in MP levels was associated with a decrease in particle length as well as width (Supplementary Figure S2B,C). The most predominant length categories were 31-40 (14\%), 41-50 (16\%), and 51-60 (11\%). The most prevalent MP width categories were 11-20 (17\%), 21-30 (29\%), and 31-40 (17\%). Multiple and varied MP polymer types were identified from across each of the five sampling sites (Figure 6). Overall, resin comprised $32 \%$ of MPs; specifically, hydrocarbon resin, phenoxy resin, and alkyd resin were most prevalent. PET and PP were also prevalent (20\% and $9 \%$, respectively). PE was not a prevalent polymer type within the February sampling period at any of the five sites (Figure 6). Fibres were detected in a higher abundance in Site 1 (A63) and Site 5 (residential) (39\%, 38\%, respectively), as opposed to $0 \%$ at Site 2 (roadside commercial), $20 \%$ at Site 3 (industrial), and $17 \%$ at Site 4 (city centre). 

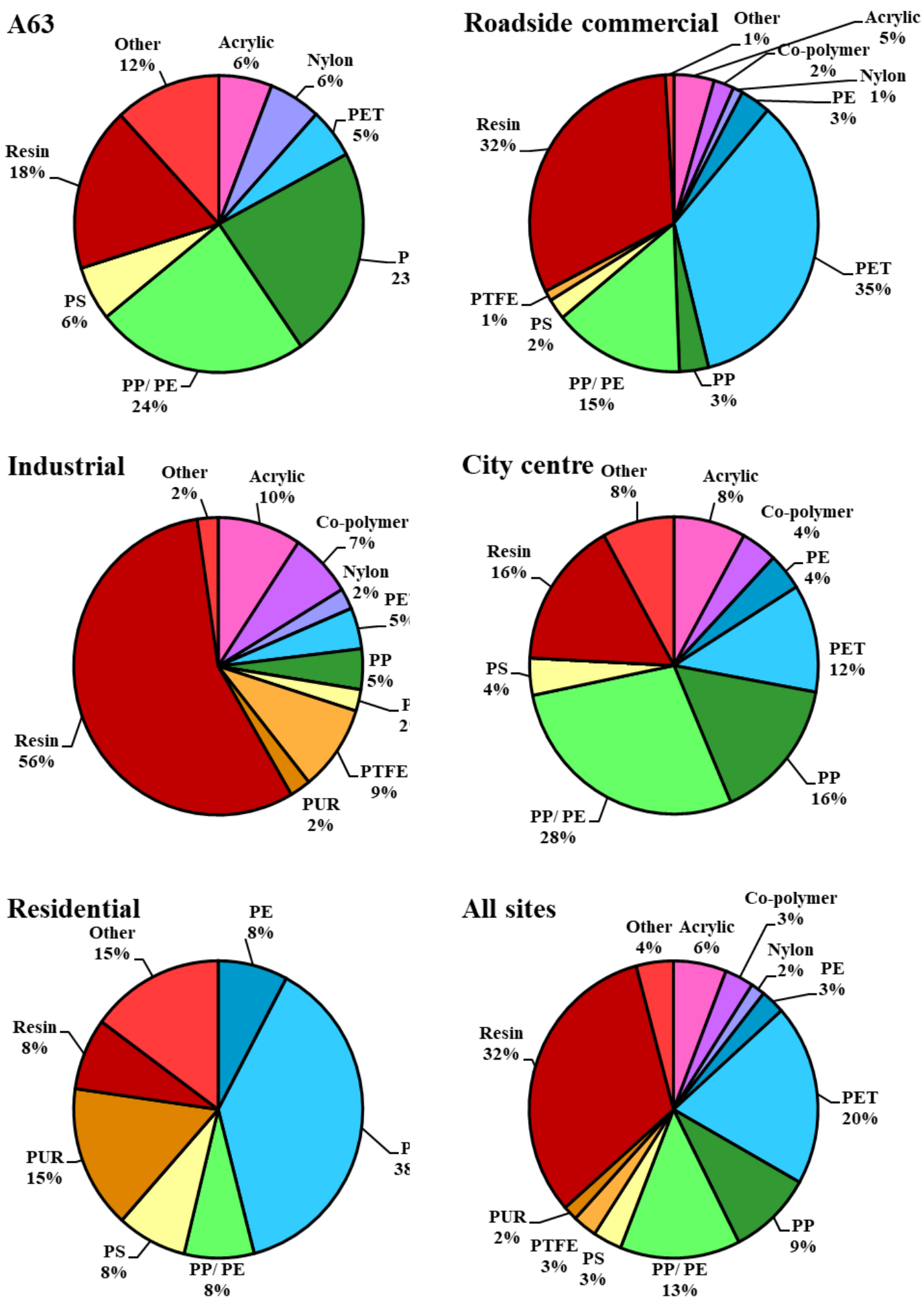

Figure 6. The proportion of MP polymer types within each sample at every site, during a single 2-week sampling period. A63 (Site 1), roadside commercial (Site 2), industrial (Site 3), city centre (Site 4), and residential (Site 5), and the overall proportion across "all sites" combined. Abbreviations: EVA, ethylene vinyl acetate; PE, polyethylene; PET, polyethylene terephthalate; PMMA, polymethylmethacrylate; PP, polypropylene; PP/PE, polypropylene-polyethylene co-polymer; PS, polystyrene; PTFE, polytetrafluoroethylene; PUR, polyurethane; resin, including alkyd, hydrocarbon, and phenoxy resin. 


\section{Discussion}

This 13-month study conducted at sampling Site 1, alongside a major trunk road, the A63, evidenced mean levels of $3055 \pm 5072 \mathrm{MP} \mathrm{m}^{-2}$ day $^{-1}$ (79-18,996 range, 1164 median) and, as such, represents the highest mean level of "bulk" outdoor atmospheric deposited MPs reported, to date, in the literature (Table 1). Other outdoor atmospheric MP deposition investigations report mean average levels ranging from 10-712 $\mathrm{MP} \mathrm{m}^{-2}$ day $^{-1}$ (Table 1). A suite of quality control and quality assurance measures were employed herein, quantifying background contamination, and using combined $\mu$ FTIR validation to add weight to these findings. In contrast to the current literature, a high abundance of film-shaped MPs, specifically PE and nylon MP types, has been observed.

MPs were identified within all sampling Site 1 (A63) samples collected during the 13-month longitudinal study, highlighting that this lower atmospheric environment within Kingston Upon Hull, U.K., is contaminated with high levels of MPs. The site represents a zone in which many forms of human activity take place, from residential, commercial, and office-based work to industrial and heavy vehicular traffic flow. The abundant thin, transparent, and flimsy "film"-shaped particles [25] made up 67\% of the MPs identified. No other studies report an abundance of this shape category, with others reporting fibrous $[15,16]$ and fragmented $[17,18]$ as the predominant shapes. The film-shaped MPs identified within this study alone had a greater mean level, $2151 \pm 3880 \mathrm{MP} \mathrm{m}^{-2} \mathrm{day}^{-1}$ (82-14,368 range), than the total MP levels reported within similar studies (Table 1).

PE was the most abundant MP polymer type detected, similarly to other atmospheric studies [16-18,23]. However, another U.K. study comprising an urban London sampling site reported a high abundance of PAN and low PE [20]. Wright et al. sampled over a one-month period and reported high levels of PAN fibres $\left(712 \pm 162 \mathrm{MP} \mathrm{m}^{-2} \mathrm{day}^{-1}\right)$. In contrast, herein, only one PAN particle was identified throughout the 13-month sampling period. Bordering the U.K., an Irish study conducted outdoors reported predominantly PET fibres of $100 \mathrm{MP}$ fibres $\mathrm{m}^{-2} \mathrm{day}^{-1}$ [21]. Work by the current authors conducted across 20 indoor home settings detected PET fibres as most common, followed by PP, then nylon, with a total MP level of $1414 \pm 1022 \mathrm{MP} \mathrm{m}^{-2}$ day $^{-1}$ (Jenner et al., 2021). This suggests that local sources and different human activities within different areas affect MP types and levels. Additionally, the outdoor levels measured within this study highlight the possibility of outdoor "hotspots" having similar, or exceeding, MP levels compared to an indoor environment, where levels are reported as typically being the highest [7,24,28]. PE was comprised of $42 \%$ film-shaped particles within this study, suggesting that likely sources are degraded containers, packaging, and carrier bags with a thin, "film-like" structure [25,29]. Nylon, an MP polymer which has already been highlighted as hazardous for inhalation at industrial levels of exposure [12], was also observed in high abundance in this study, and represented $35 \%$ of film shaped particles or $28 \%$ of the total MP count. Similar to other atmospheric MP studies (Table 1), no foam or spherical MPs were identified. In addition, of note, the quantity of MP polymer types $(n=25)$ detected herein was exceptionally high when compared with similar investigations (Table 1). However, the 13-month sampling period, as well as the high number of particles taken to chemical composition analysis ( $\mathrm{n}=8481$ for Site $1 ; \mathrm{n}=9983$ total), could be responsible for the higher levels reported. In many atmospheric MP studies, it is common practice to apply observational criteria [3], chemical analysis on a relatively small subset of particles $[6,15,23]$, or chemical analysis on a small subset of specific particle shapes $[16,20]$ before extrapolation, which may skew conclusions reached regarding the main polymer types.

Still focusing on the dataset from the 13-month single-site (A63) analysis, the particle size trend, which showed an increase in levels of the smaller particles, is commonly reported within atmospheric MP literature $[17,18]$, as well as a decrease just before the method detection limit is reached [15,16] (Figure 3B,C). Weathered particles may cause an inability to gain a $>70 \%$ polymeric match rate, and there could also be difficulty observing the smallest of particles due to heavy particle load and equipment constraints that lead to a situation where the smallest of size ranges cannot be analysed $[15,16]$. With MP lengths as 
small as $8 \mu \mathrm{m}$ and widths as small as the method detection limit $(5 \mu \mathrm{m})$, inhalable-sized particles were captured within samples. This highlights the importance of developing analytical methodologies and techniques that include respirable and nanoplastic size ranges, which will aid the understanding of which MPs are likely to be inhaled daily.

In terms of spatial variation in MP levels, the roadside commercial sampling Site 2 had the highest MP levels compared to the other sites (Figure 5) for the 2-week snapshot of sampling across all the sites. While Site 2 (commercial roadside) was in a zone with high human activity in terms of traffic and footfall, it was hypothesised that Site 1 (A63), representing a trunk road with relatively heavier traffic flow, would have the highest MP levels, yet it did not. Site 5 (residential) had the lowest MP levels within the singlesampling period. This residential zone is considered the lowest in human activity, with playing fields and a distance away from commercial and industrial zones, allowing for a greater air dilution. It is important to note that the difference between sampling sites was not significant $(p=0.406)$. It is also difficult to draw conclusions based on this single set of results, illustrating the importance of conducting long-term sampling analysis.

The sizes of MPs within the snapshot 2-week sampling period followed the same trend as the 13-month investigation and other similar studies within literature $[17,18]$; there was an increase in MP levels with decrease in both particle length and width. Compared to Site 1, there were a higher proportion of fragment particles from the five combined sites. However, both fragment (52\%) and film ( $42 \%)$ particles dominated the five-site investigation, similar to Site 1 results. Whilst it is common to identify an abundance of fragmented MPs within outdoor atmospheric samples $[17,18]$, it is not common to identify film-shaped MPs in such high abundance.

The predominant MP polymer type detected during the spatial, 2-week sampling period across all sites differed compared with the 13-month single-site analysis. In contrast to the PE polymer detected at Site 1 overall, resin was predominant during the 2-week snapshot sampling. Resin is used in rubber tyres and road markings, paints, and industrial use [20]. Almost half of the resin particles detected within the five-site investigation were reported as fragment in shape, explaining why the investigation had a higher prevalence of fragmented MPs compared to the Site 1 investigation. It is not surprising to see lower levels at a residential site (Site 5) and higher levels in zones where traffic and manufacturing are more common (Figure 6). The lack of PE MPs from all five sampling sites highlights the importance of sampling numerous months, as fluctuations in polymer types is clear. The presence of fibres within samples can be considered an indicator of urbanisation, high human activity [6], or proximity to residential areas in which fibres can dominate indoor samples [24]. Results show that in Site 1, of highest human activity (A63), and Site 5, of a residential zone, fibrous MPs were highest. Other sites in which nonfibrous particles were more prevalent suggest a nontextile source of MPs and/or degradation of MPs into smaller fragmented shapes. Interestingly, PET MPs, known to be extremely abundant within indoor samples [24], were not abundant within the residential Site 5 samples.

Since the aim of this study was not to focus on transport and sources of MPs, only rainfall was investigated as a potential significant meteorological event. In this study, no relationship, using a Spearman's correlation test, between MP levels and rainfall was observed (Figure 2). A more in-depth investigation into other meteorological events is needed before the effects of such weather conditions can be determined. Many such factors will influence MP transport and it is therefore unsurprising that no relationship with rainfall was found. On the other hand, many studies do support a relationship between rainfall and particle and/or MP fallout, yet the majority do not report a significance between the variables [16-18,30]. A final, and somewhat unique variable to consider herein, is the impact, if any, that the pandemic-induced national lockdown may have had on influencing the sampling Site 1 (A63) 13-month dataset. The lockdown months involved high MP levels relative to selected other months, with April and May accounting for $21 \%$ of total MPs identified within Site 1. It is possible that vehicular and weather events resuspended particles already present within the environment, even while the human activity remained 
low due to lockdown. July, the month in which schools, nonessential shops, and venues reopened, accounted for $46 \%$ of the total MPs identified in the Site 1 sample (Figure S1). Other months, pre- and post-lockdown, largely remained below the MP mean and median (Figure S1). As further data becomes published, the influence of the pandemic lockdown periods on levels of atmospheric MPs may become clearer.

While it is unclear what the main sources and drivers of outdoor MP levels and types are in specific locations, their levels are nonetheless high with a mean of $3055 \pm 5072 \mathrm{MP} \mathrm{m}^{-2}$ day $^{-1}$ (79-18,996 range, 1164 median), consisting mainly of films comprising PE and nylon (Table 1, Figure 4). The size range of MPs detected were mainly in the 5-40 $\mu \mathrm{m}$ length category (Figure $3 \mathrm{C}$ ), raising concerns relating to human ability to inhale particles of this size range, whether they enter lungs, and what might be the health consequences. There has been just one published study of MP-induced human health impacts, caused by nylon fibres, in the occupational setting of nylon flock-making [31]. Workers displaying lung disease had been typically exposed to nylon fibres of size range $10-15 \mu \mathrm{m}$ width and $1000 \mu \mathrm{m}$ length at an average respirable particulate concentration of $2.2 \mathrm{mg} \mathrm{m}^{3}$ [31], significantly more particles experienced than in an outdoor environment yet consisting of the same particle size (width) range. In a controlled laboratory exposure study, human lung cell cultures were recently exposed to nylon fibres (of approximate size shape $10 \mu \mathrm{m} \times 30 \mu \mathrm{m}$ ), at a level of 5000 fibres, and damage to the lung cell growth and development observed [32]. In parallel work, a total of 39 MPs were identified within 11 of the 13 human lung biopsy tissue samples, with $3.00 \pm 2.55 \mathrm{MPs}$ for individual tissue samples, adjusted to $1.42 \pm 1.50$ for MP/g tissue sample (Jenner et al., in review). Of these, 12 polymer types were identified, with PP $(23 \%)$, PET (18\%), resin $(15 \%)$, and PES $(10 \%)$ the most abundant (Jenner et al., in review). Given the levels of MPs reported herein and previously, as well as potential human health impacts from inhalation, the inclusion of such particles as an emerging contaminant should be considered for inclusion within air quality modelling and monitoring practices.

\section{Conclusions}

In conclusion, outdoor urban environments contain significant levels of MPs which range across zones and season from $79-18,996 \mathrm{MP} \mathrm{m}^{-2}$ day $^{-1}$, with a mean of $3055 \mathrm{MP} \mathrm{m}^{-2}$ day $^{-1} \pm 5072$ (mean $\pm \mathrm{SD}$ ) (1164 median) for Site 1 over a 13-month sampling period. A range of $522-3617 \mathrm{MP} \mathrm{m}^{-2}$ day $^{-1}$, with a mean of $1500 \pm 1279 \mathrm{MP} \mathrm{m}^{-2}$ day $^{-1}$ (mean \pm SD) (1012 median) was determined across the five sites over the 2-week sampling period. The most detected MPs were PE, nylon, and resin, and the most abundant size dimensions detected were 5-50 $\mu \mathrm{m}$, within the size range detected in nylon flock workers with lung disease and found to harm lung cells in culture [31,32]. The findings herein can inform laboratory exposures using human lung cell cultures, as part of our future work to investigate environmentally relevant levels, using the most common chemical types of MPs detected (PE and nylon, plus others), and determine any human health impacts.

Supplementary Materials: The following supporting information can be downloaded at: https: / / www.mdpi.com/article/10.3390/atmos13020265/s1, Figure S1: Chart showing the MP levels $\left(\mathrm{MP} \mathrm{m}^{-2}\right.$ day $\left.^{-1}\right)$ during each 2-week sampling period per month, for the 13-month investigation of Site 1; Figure S2: MP characteristics observed in the atmospheric samples obtained from all sites, from a single 2-week sampling period. A) shape, B) length, and C), width. Table S1: The background level of MPs detected within procedural and laboratory blanks for the 13-month sampling at Site 1 and the 2-week investigation of 5 sampling sites; Methods M1: Calculation used to determine the LOD/LOQ for each MP polymer.

Author Contributions: Conceptualisation, methodology, investigation, data curation, visualisation, writing: L.C.J.; formal analysis: L.C.J., E.C., R.L.J. and E.D.; funding acquisition, project administration, supervision, writing: J.M.R. and L.R.S.; conceptualisation and methodology: D.W. All authors have read and agreed to the published version of the manuscript. 
Funding: This research did not receive any specific grant funding. This work was funded by a PhD scholarship in the "Human Health and Emerging Environmental Contaminants" cluster funded by the University of Hull to L.C.J.

Institutional Review Board Statement: This work did not involve human or other animal subjects.

Informed Consent Statement: No humans were involved in this study.

Data Availability Statement: The corresponding author agrees to share the datasets on request.

Conflicts of Interest: The authors declare no conflict of interest.

\section{References}

1. Horton, A.A.; Dixon, S.J. Microplastics: An introduction to environmental transport processes. Wiley Interdiscip. Rev. Water. 2017, 5, e1268. [CrossRef]

2. Hartmann, N.B.; Hüffer, T.; Thompson, R.C.; Hassellöv, M.; Verschoor, A.; Daugaard, A.E.; Rist, S.; Karlsson, T.M.; Brennholt, N.; Cole, M.; et al. Are We Speaking the Same Language? Recommendations for a Definition and Categorization Framework for Plastic Debris. Environ. Sci. Technol. 2019, 53, 1039-1047. [CrossRef] [PubMed]

3. Hidalgo-Ruz, V.; Gutow, L.; Thompson, R.C.; Thiel, M. Microplastics in the marine environment: A review of the methods used for identification and quantification. Environ. Sci. Technol. 2012, 46, 3060-3075. [CrossRef] [PubMed]

4. Hale, R.C.; Seeley, M.E.; La Guardia, M.J.; Mai, L.; Zeng, E.Y. A Global Perspective on Microplastics. J. Geophys. Res. Oceans. 2020 125, 1-40. [CrossRef]

5. Chen, G.; Feng, Q.; Wang, J. Mini-review of microplastics in the atmosphere and their risks to humans. Sci. Total Environ. 2020, 703, 135504. [CrossRef]

6. González-Pleiter, M.; Edo, C.; Aguilera, Á.; Viúdez-Moreiras, D.; Pulido-Reyes, G.; González-Toril, E.; Osuna, S.; de Diego-Castilla G.; Leganés, F.; Fernández-Piñas, F.; et al. Occurrence and transport of microplastics sampled within and above the planetary boundary layer. Sci. Total Environ. 2021, 761, 143213. [CrossRef]

7. Dris, R.; Gasperi, J.; Mirande, C.; Mandin, C.; Guerrouache, M.; Langlois, V.; Tassin, B. A first overview of textile fibers, including microplastics, in indoor and outdoor environments. Environ. Pollut. 2017, 221, 453-458. [CrossRef] [PubMed]

8. Danopoulos, E.; Twiddy, M.; Rotchell, J.M. Microplastic contamination of drinking water: A systematic review. PLoS ONE 2020, 15, e0236838. [CrossRef]

9. Danopoulos, E.; Jenner, L.; Twiddy, M.; Rotchell, J.M. Microplastic contamination of salt intended for human consumption: A systematic review and meta-analysis. SN Appl. Sci. 2020, 2, 1950. [CrossRef]

10. Danopoulos, E.; Jenner, L.C.; Twiddy, M.; Rotchell, J.M. Microplastic contamination of seafood intended for human consumption: A systematic review and meta-analysis. Environ. Health Perspect. 2020, 128, 126002. [CrossRef] [PubMed]

11. Gasperi, J.; Wright, S.L.; Dris, R.; Collard, F.; Mandin, C.; Guerrouache, M.; Langlois, V.; Kelly, F.J.; Tassin, B. Miroplastics in air: Are we breathing it in? Curr. Opin. Environ. Sci. Health 2018, 1, 1-5. [CrossRef]

12. Prata, J.C. Airborne microplastics: Consequences to human health? Environ. Pollut. 2018, 234, 115-126. [CrossRef] [PubMed]

13. Pauly, J.L.; Stegmeier, S.J.; A Allaart, H.; Cheney, R.T.; Zhang, P.J.; Mayer, A.G.; Streck, R.J. Inhaled cellulosic and plastic fibers found in human lung tissue. Cancer Epidemiol. Biomarkers Prev. 1998, 7, 419-428.

14. Amato-Lourenço, L.F.; Carvalho-Oliveira, R.; Júnior, G.R.; dos Santos Galvão, L.; Ando, R.A.; Mauad, T. Presence of airborne microplastics in human lung tissue. J. Hazard. Mater. 2021, 416, 126124. [CrossRef] [PubMed]

15. Dris, R.; Gasperi, J.; Saad, M.; Mirande, C.; Tassin, B. Synthetic fibers in atmospheric fallout: A source of microplastics in the environment? Mar. Pollut. Bull. 2016, 104, 290-293. [CrossRef] [PubMed]

16. Cai, L.; Wang, J.; Peng, J.; Tan, Z.; Zhan, Z.; Tan, X.; Chen, Q. Characteristic of microplastics in the atmospheric fallout from Dongguan city, China: Preliminary research and first evidence. Environ. Sci. Pollut. Res. 2017, 24, 24928-24935. [CrossRef]

17. Klein, M.; Fischer, E.K. Microplastic abundance in atmospheric deposition within the Metropolitan area of Hamburg, Germany. Sci. Total Environ. 2019, 685, 96-103. [CrossRef]

18. Allen, S.; Allen, D.; Phoenix, V.; Le Roux, G.; Jiménez, P.D.; Simonneau, A.; Binet, S.; Galop, D. Atmospheric transport and deposition of microplastics in a remote mountain catchment. Nat. Geosci. 2019, 12, 339-344. [CrossRef]

19. Brahney, J.; Hallerud, M.; Heim, E.; Hahnenberger, M.; Sukumaran, S. Plastic rain in protected areas of the United States. Science 2020, 368, 1257-1260. [CrossRef] [PubMed]

20. Wright, S.L.; Ulke, J.; Font, A.; Chan, K.L.A.; Kelly, F.J. Atmospheric microplastic deposition in an urban environment and an evaluation of transport. Environ. Int. 2020, 136, 105411. [CrossRef]

21. Roblin, B.; Ryan, M.; Vreugdenhil, A.; Aherne, J. Ambient Atmospheric Deposition of Anthropogenic Microfibers and Microplastics on the Western Periphery of Europe (Ireland). Environ. Sci. Technol. 2020, 54, 11100-11108. [CrossRef]

22. Huang, Y.; He, T.; Yan, M.; Yang, L.; Gong, H.; Wang, W.; Qing, X.; Wang, J. Atmospheric transport and deposition of microplastics in a subtropical urban environment. J. Hazard. Mater. 2021, 416, 126168. [CrossRef] [PubMed]

23. Szewc, K.; Graca, B.; Dołęga, A. Atmospheric deposition of microplastics in the coastal zone: Characteristics and relationship with meteorological factors. Sci. Total Environ. 2020, 143272. [CrossRef] [PubMed] 
24. Jenner, L.C.; Sadofsky, L.R.; Danopoulos, E.; Rotchell, J.M. Household indoor microplastics within the Humber region (United Kingdom): Quantification and chemical characterisation of particles present. Atmos. Environ. 2021, $259,118512$. [CrossRef]

25. Free, C.M.; Jensen, O.P.; Mason, S.A.; Eriksen, M.; Williamson, N.J.; Boldgiv, B. High-levels of microplastic pollution in a large, remote, mountain lake. Mar. Pollut. Bull. 2014, 85, 156-163. [CrossRef] [PubMed]

26. Vianello, A.; Jensen, R.L.; Liu, L.; Vollertsen, J. Simulating human exposure to indoor airborne microplastics using a Breathing Thermal Manikin. Sci. Rep. 2019, 9, 8670. [CrossRef] [PubMed]

27. Horton, A.A.; Cross, R.K.; Read, D.S.; Jürgens, M.D.; Ball, H.L.; Svendsen, C.; Vollertsen, J.; Johnson, A.C. Semi-automated analysis of microplastics in complex wastewater samples. Environ. Pollut. 2021, 268, 115841. [CrossRef] [PubMed]

28. Zhang, Q.; Zhao, Y.; Du, F.; Cai, H.; Wang, G.; Shi, H. Microplastic Fallout in Different Indoor Environments. Environ. Sci. Technol. 2020, 54, 6530-6539. [CrossRef] [PubMed]

29. Plastics Europe. Plastics - The Facts 2020. An Analysis of European Plastics Production, Demand and Waste Data; Plastics: Brussels, Belgium, 2020; pp. 1-64. Available online: https:/ /www.plasticseurope.org/en/resources/publications/4312-plastics-facts-2020 (accessed on 1 February 2022).

30. Dris, R.; Gasperi, J.; Rocher, V.; Saad, M.; Renault, N.; Tassin, B. Microplastic contamination in an urban area: A case study in Greater Paris. Environ. Chem. 2015, 12, 592. [CrossRef]

31. Burkhart, J.; Jones, W.; Porter, D.W.; Washko, R.M.; Eschenbacher, W.L.; Castellan, R.M. Hazardous occupational exposure and lung disease among nylon flock workers. Am. J. Ind. Med. 1999, 36, 145-146. [CrossRef]

32. van Dijk, F.; Song, S.; van Eck, G.W.A.; Wu, X.; Bos, I.S.T.; Boom, D.H.A.; Kooter, I.M.; Spierings, D.C.J.; Wardenaar, R.; Cole, M.; et al. Inhalable Textile Microplastic Fibers Impair Airway Epithelial Growth. Biorxiv 2021. Biorxiv:2021.01.25.428144. [CrossRef] 